\title{
Effects of Asian dust-derived particulate matter on ST-elevation myocardial infarction: retrospective, time series study
}

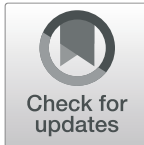

Suji Lee ${ }^{1}$, Whanhee Lee ${ }^{2}$, Eunil Lee ${ }^{3}$, Myung Ho Jeong ${ }^{4}$, Seung-Woon Rha ${ }^{5}$, Chong-Jin Kim ${ }^{6}$, Shung Chull Chae ${ }^{7,8}$, Hyo-Soo Kim ${ }^{9}$, Hyeon-Cheol Gwon ${ }^{10}$ and Ho Kim ${ }^{1,2^{*}}$

\begin{abstract}
Background: Dust storms affect human health by impairing visibility and promoting interactions with microscopic organisms, such as bacteria and fungi. Although ST-elevation MI (STEMI) and non-ST-elevation MI (NSTEMI) differ mechanistically, few studies have investigated the incidence of cardiovascular diseases according to infarction type; these studies have yielded inconsistent findings. This study aimed to examine whether PM size $\left(<2.5 \mu \mathrm{m}\left(\mathrm{PM}_{2.5}\right)\right.$ and $\left.<10 \mu \mathrm{m}\left(\mathrm{PM}_{10}\right)\right)$ modifies the effect of Asian dust on acute myocardial infarction (AMI), with separate analyses for STEMI and NSTEMI.
\end{abstract}

Methods: MI-related data from 9934 emergency visits were collected from the Korea AMI Registry from 2005 to 2017. Asian dust events were defined as days with visibility of $\leq 10 \mathrm{~km}$. Generalized linear models were used to analyze data with natural cubic splines. To examine potential modifiers, analyses were stratified by age, smoking status, and body mass index (BMI).

Results: No significant associations were observed between Asian dust and AMI. By adjusting for different lag structures, a significant effect was exclusively observed in STEMI. For moving average lags, the largest value at lag 5 (relative risk [RR] 1.083; 95\% confidence interval [CI], 1.007-1.166) for single and lags 0-7 (RR 1.067; 95\% Cl: 1.0021.136) was observed for $\mathrm{PM}_{25}$; for $\mathrm{PM}_{10}$, the largest significant effect was observed at lag 4 (RR 1.075; 95\% Cl: 1.0101.144) for single and lags $0-7$ (RR 1.067; 95\% Cl: 1.002-1.136). RRs were significantly higher in <65-year-olds than in $\geq 65$-year-olds. Additionally, RRs between the $\mathrm{BMl}<25$ and $\mathrm{BMl} \geq 25$ groups were not different; statistically significant effects were observed for concentration at lags 0-5 (RR: 1.073; 95\% Cl: 1.002-1.150) and lags 0-6 (RR: 1.071; 95\% Cl: 1.001-1.146) in the $\mathrm{BMl}<25$ group. A negative exposure-response association was observed between daily average visibility-adjusted PM and STEMI and daily average visibility-adjusted PM in <65-year-olds.

Conclusions: Reducing $\mathrm{PM}_{2.5}$ and $\mathrm{PM}_{10}$ emissions, particularly during the days of Asian dust, may be crucial and reduce STEMI and AMI incidence among < 65-year-olds. These results indicate that the Asian dust alarm system needs revision to protect vulnerable populations.

Keywords: Particulate matter, Myocardial infarction, Asian dust, Air pollution, Health effect

\footnotetext{
* Correspondence: hokim@snu.ac.kr

${ }^{1}$ Institute of Health and Environment, Seoul National University, Gwanak-ro, Seoul 08826, Republic of Korea

${ }^{2}$ Department of Biostatistics and Epidemiology, Graduate School of Public Health, Seoul National University, Gwanak-gu, Seoul 00826, Republic of Korea Full list of author information is available at the end of the article
}

C The Author(s). 2021 Open Access This article is licensed under a Creative Commons Attribution 4.0 International License, which permits use, sharing, adaptation, distribution and reproduction in any medium or format, as long as you give appropriate credit to the original author(s) and the source, provide a link to the Creative Commons licence, and indicate if changes were made. The images or other third party material in this article are included in the article's Creative Commons licence, unless indicated otherwise in a credit line to the material. If material is not included in the article's Creative Commons licence and your intended use is not permitted by statutory regulation or exceeds the permitted use, you will need to obtain permission directly from the copyright holder. To view a copy of this licence, visit http://creativecommons.org/licenses/by/4.0/. The Creative Commons Public Domain Dedication waiver (http://creativecommons.org/publicdomain/zero/1.0/) applies to the data made available in this article, unless otherwise stated in a credit line to the data. 


\section{Background}

Dust storms affect human health by impairing visibility and promoting interactions with microscopic organisms, such as bacteria and fungi [1]. They have recently been associated with diseases and adverse health effects and are being recognized as a health risk. Considerable epidemiological research has been published on cardiovascular impacts of dust storms in East Asian countries, such as China [2] and Japan [3, 4], as well as southern Europe [5] and North America [6]. These adverse health effects include asthma, respiratory diseases, cardiovascular diseases, and mortality [2, 4-6]. By contrast, some studies have observed no association between dust storms and cardiovascular disease in either emergency department or hospital admissions [7].

There is an increasing evidence that increased exposure to particulate matter (PM) leads to cardiovascular disease, particularly among patients with a history of myocardial infarction (MI) [8-11]. Although STelevation MI (STEMI) and non-ST-elevation MI (NSTE MI) differ mechanistically [12], few studies have investigated the incidence of cardiovascular diseases according to infarction type; these studies have yielded inconsistent findings. A New York-based study initially suggested that exposure to $\mathrm{PM}$ size $<2.5 \mu \mathrm{m}\left(\mathrm{PM}_{2.5}\right)$ increased the risk of STEMI, unlike NSTEMI [9]. Moreover, studies from Belgium and Utah (US) reported consistent results $[8,11]$. Conversely, other studies failed to demonstrate the effect of $\mathrm{PM}_{2.5}$ on STEMI risk $[13,14]$.

The European project "MED-PARTICLES" underscored that the adverse health effect of the desert component of PM can be affected by concentrations of anthropogenicderived PM size < $10 \mu \mathrm{m}\left(\mathrm{PM}_{10}\right)$ [15]. However, past approaches that investigated the health effects of PM and Asian dust separately analyzed each component, whereas few researches simultaneously studied the two effects. Additionally, various natural crustal elements $\left(\mathrm{Ca}^{2+}, \mathrm{Mg}^{2+}\right.$, $\mathrm{Na}^{+}, \mathrm{K}^{+}$), anthropogenic pollutants $\left(\mathrm{Pb}, \mathrm{As}, \mathrm{NO}_{\mathrm{x}}\right)$, microorganisms, fungal spores, chemical components, and gaseous pollutants can also be mixed and carried in the dust [16]. It is possible that dust event-associated health effects involving PM are different from those associated with dust events alone [17]; therefore, it is necessary to research the health effects of dust storms with PM.

Therefore, this study aimed to evaluate the association between AMI and Asian dust with PM, and assess the variation of the association according to infarction type (STEMI and NSTEMI), age group, body mass index (BMI), and smoking status.

\section{Methods}

\section{Data collection}

The KAMIR is a prospective study of approximately 37, 880 patients in 57 general emergency rooms of Korean hospitals that collects data using a standardized case report form. The rationale and design of this nationwide mandatory registration have been previously explained [18]. This study included patients from the KAMIR who presented with AMI to the Seoul hospital emergency rooms between 2005 and 2017 and for whom $\mathrm{PM}_{2.5}$ data were available. Of these, patients with inadequate information were excluded. The first medical contact time was defined as the time of the primary manifestation of AMI symptoms. In addition, stratified analyses were performed by age, smoking status, and MI status (STEMI and NSTEMI).

Climate data were obtained from the Korean Meteorological Administration, including those on the daily mean temperature, humidity, sea level pressure, and visibility from 2005 to 2017. Based on previous studies, we defined Asian dust events as days when visibility was < $10 \mathrm{~km}[3,4] . \mathrm{PM}_{10}$ data were obtained from the National Institute of Environmental Research in Korea, whereas $\mathrm{PM}_{2.5}$ data were collected from 27 monitoring sites managed by the Seoul Research Institute of Public Health and Environment.

\section{Statistical analysis}

The time-series data for this ecological study design were analyzed using generalized linear models to accommodate the nonlinear relationships of emergency visits for AMI. Natural cubic spline functions were used to consider non-linearity for time and weather variables. In the basic model, single lag day effects of Asian dust were examined from the current day (lag 0 ) to the sixth day, adjusting for meteorological effects that could affect AMI, including two-day moving average of temperature, current day relative humidity, and sea level pressure (lag 0 ), as covariates. In the evaluation of the hypothesis that $\mathrm{PM}_{2.5}$ and $\mathrm{PM}_{10}$ would enhance $\mathrm{MI}$ risk on Asian dust days, single- and moving average lags of $\mathrm{PM}_{2.5}$ and $\mathrm{PM}_{10}$ were included in the basic model. The largest lag days of Asian dust in the basic model were used in the PMadjusted model. Similarly, stratified analyses were conducted by age, smoking status (never smoking/past smoking/current smoking), and obesity to evaluate the potential effect of the association between Asian dust and AMI. BMI was categorized into two categories based on the standard definition as follows [19]: normal/underweight (BMI $<25 \mathrm{~kg} / \mathrm{m}^{2}$ ) and overweight/obese (BMI $\geq 25 \mathrm{~kg} / \mathrm{m}^{2}$ ).

Finally, sensitivity analyses were performed to assess the validity of the findings by modified different degrees of freedom for time trends and various temperature lag structures. Additionally, because higher relative humidity could plausibly affect visibility, models were repeated to include interaction terms between daily mean visibility and an indicator variable of high level of humidity days, 
wherein relative humidity was higher than $70 \%$ or $80 \%$, respectively. All statistical analyses were performed using R software 3.4.0 (Vienna, Austria).

\section{Results}

Table 1 presents baseline characteristics of study participants. STEMI and NSTEMI occurred in 5366 and 4497 patients, respectively. Regarding STEMI, there were $63.8 \%$ patients aged $\geq 65$ years, and $78.8 \%$ were male. Regarding NSTEMI, there were $70.78 \%$ patients aged $\geq 65$ years, and $68.4 \%$ were male. STEMI patients were more likely to be current smokers $(44.3 \%)$ than NSTEMI patients (33.5\%).

Table 2 shows the daily mean concentrations of air pollutants and weather conditions in Seoul with and without Asian dust events. Concentrations of pollutants, excluding $\mathrm{O}_{3}$, were higher during Asian dust days than during days without Asian dust events. We found that Pearson's correlation coefficients of PM concentrations was more strongly related with visibility than were other air pollutants such as $\mathrm{NO}_{2}, \mathrm{SO}_{2}, \mathrm{O}_{3}$, and $\mathrm{CO}$ (Additional file 1). In addition, after excluding relative humidity higher than $80 \%$, visibility retained a high negative correlation with PM.

Figure 1 presents the relative risks (RRs) of STEMI and NSTEMI associated with dust days, according to lag days. The largest effect was observed in STEMI patients at the lag 6 concentration (RR, 1.055; 95\% confidence interval $[\mathrm{CI}], 0.993-1.120)$, whereas that in NSTEMI patients was observed on the current day (RR, 1.046; 95\% CI, 0.963-1.136). However, the values were not significant. While evaluating the effect of PM, significant associations were observed between the RRs of NSTEMI and $\mathrm{PM}_{10}$ and between the subgroup of NSTEMI patients aged $\geq 65$ years and $\mathrm{PM}_{2.5}$ (Additional file 2).

Figure 2 illustrates the association between Asian dust exposure and onset of STEMI and NSTEMI, after adjustment for $\mathrm{PM}_{2.5}$ and $\mathrm{PM}_{10}$, by different lag structures. For STEMI, RRs increased after adjustment for $\mathrm{PM}_{2.5}$ and $\mathrm{PM}_{10}$ (for both single- and moving average lags). On considering $\mathrm{PM}_{2.5}$ in the model, the most significant effect was observed at lag 5 (RR 1.083; 95\% CI, 1.0071.166) for single lags and lags 0-7 (RR 1.067; 95\% CI: 1.002-1.136) for moving average lags. In the course of controlling for $\mathrm{PM}_{10}$ in the model, the largest significant effect was observed at lag 4 (RR 1.075; 95\% CI: 1.010 1.144) for single lags and lags $0-7$ (RR 1.067; 95\% CI: 1.002-1.136) for moving average lags. On the contrary, Asian dust exposure had no significant risk for the onset of NSTEMI for both single- and moving average lags.

Figure 3 illustrates clearly negative and linear exposure-response relationships between daily visibility at lag 5 and STEMI in those aged $<65$ years. As $\mathrm{PM}_{2.5}$ demonstrated a larger impact of Asian dust on the incidence of AMI, using an age group- and BMI-based stratification analysis, the effect of $\mathrm{PM}_{2.5}$ was further examined (Fig. 4). A significantly greater risk was observed in the $<65$-year-old age group for single lags at lag 5

Table 1 Characteristics of patients with myocardial infarction in Korea during 2005-2017 (N=9934)

\begin{tabular}{|c|c|c|c|c|}
\hline \multirow[t]{2}{*}{ Characteristic } & \multicolumn{2}{|l|}{ STEMI } & \multicolumn{2}{|l|}{ NSTEMI } \\
\hline & $N=5366$ & $54.0 \%$ & $N=4497$ & $45.2 \%$ \\
\hline \multicolumn{5}{|l|}{ Age } \\
\hline$<65$ years $(n=3277)$ & 1893 & 35.3 & 1288 & 28.7 \\
\hline$\geq 65$ years $(n=6657)$ & 3424 & 63.8 & 3183 & 70.8 \\
\hline Mean \pm SD & $70.0 \pm 14.2$ & & $72.4 \pm 14.1$ & \\
\hline Male $(n=7326)$ & 4194 & 78.3 & 18,204 & 68.4 \\
\hline \multicolumn{5}{|l|}{ Smoking } \\
\hline Never & 2111 & 39.1 & 2165 & 49.3 \\
\hline Ex & 811 & 14.9 & 7,57 & 17.2 \\
\hline Current & 2323 & 44.3 & 1474 & 33.5 \\
\hline Unknown history & 121 & & 101 & \\
\hline \multicolumn{5}{|l|}{ Medical history } \\
\hline Hypertension & 2577 & 49.4 & 2583 & 58.5 \\
\hline Diabetes mellitus & 1391 & 26.7 & 1486 & 33.8 \\
\hline Dyslipidemia & 653 & 12.5 & 708 & 16.1 \\
\hline \multicolumn{5}{|l|}{ BMI } \\
\hline Normal weight $\left(\mathrm{BMI}<25 \mathrm{~kg} / \mathrm{m}^{2}\right)$ & 2852 & 53.2 & 2468 & 54.9 \\
\hline Overweight (BMI $\geq 25 \mathrm{~kg} / \mathrm{m}^{2}$ ) & 1814 & 33.9 & 1559 & 34.7 \\
\hline
\end{tabular}

(Missing = 71). STEMI ST-elevation myocardial infarction, NSTEMI non-ST-elevation myocardial infarction, STD standard deviation, BMI body mass index 
Table 2 Mean level of air pollution on Asian dust- (visibility $\leq 10 \mathrm{~km}$ ) and non-Asian dust days

\begin{tabular}{llll}
\hline & Mean level on Asian dust days $(\boldsymbol{n}=\mathbf{1 3 0 1})$ & Mean level on non-Asian dust days $(\boldsymbol{n}=\mathbf{2 8 7 5})$ & $\boldsymbol{P}$ value \\
\hline Air pollutant concentrations & & & $<0.0001$ \\
$\mathrm{CO}(\mathrm{ppm})$ & $0.8 \pm 0.4$ & $0.6 \pm 0.3$ & 0.102 \\
$\mathrm{O}_{3}(\mathrm{ppb})$ & $31.6 \pm 19.5$ & $32.6 \pm 16.9$ & $<0.0001$ \\
$\mathrm{NO}_{2}(\mathrm{ppb})$ & $38.5 \pm 12.9$ & $31.3 \pm 11.7$ & $<0.0001$ \\
$\mathrm{SO}_{2}(\mathrm{ppb})$ & $6.1 \pm 2.7$ & $5.1 \pm 1.6$ & $<0.0001$ \\
$\mathrm{PM}_{10}\left(\mu \mathrm{g} / \mathrm{m}^{3}\right)$ & $70.6 \pm 41.8$ & $42.3 \pm 20.0$ & $<0.0001$ \\
$\mathrm{PM}_{2.5}\left(\mu \mathrm{g} / \mathrm{m}^{3}\right)$ & $39.1 \pm 17.1$ & $22.1 \pm 8.9$ & \\
Weather conditions & & $11.95 \pm 11.15$ & $<0.0001$ \\
Mean temperature $\left({ }^{\circ} \mathrm{C}\right)$ & $13.76 \pm 9.22$ & $55.26 \pm 13.36$ & $<0.0001$
\end{tabular}

$\mathrm{CO}$ carbon monoxide, $\mathrm{O}_{3}$ ozone, $\mathrm{NO}_{2}$ nitrogen dioxide, $\mathrm{SO}_{2}$ sulfur dioxide, $\mathrm{PM}_{10}$ particulate matter with a median aerodynamic diameter $\leq 10 \mu \mathrm{m} ; \mathrm{ppb}, \mathrm{PM} 2.5$, fine particulate air matter with an aerodynamic diameter $<2.5 \mu \mathrm{m}$; ppb, parts per billion; ppm, parts per million

(RR 1.134; 95\% CI: 1.028-1.249) and moving average lags at lags $0-5$ (RR, 1.083; 95\% CI, 1.007-1.166). RRs between the $\mathrm{BMI}<25 \mathrm{~kg} / \mathrm{m}^{2}$ and $\mathrm{BMI} \geq 25 \mathrm{~kg} / \mathrm{m}^{2}$ groups were not different; however, significant effects were observed for the $\mathrm{PM}_{2.5}$ concentrations at lags $0-5$ (RR, $1.073 ; 95 \% \mathrm{CI}, 1.002-1.150)$ in the $\mathrm{BMI}<25 \mathrm{~kg} / \mathrm{m}^{2}$ group. When $\mathrm{PM}_{10}$ was considered in the model, a similar pattern was observed with $\mathrm{PM}_{2.5}$ for both age group and BMI; however, a significant effect was exclusively observed in <65-year-old age group (Additional file 3).

Although our results did not achieve statistical significance owing to the small sample size, RRs were higher in the past smoking group than in the never smoking

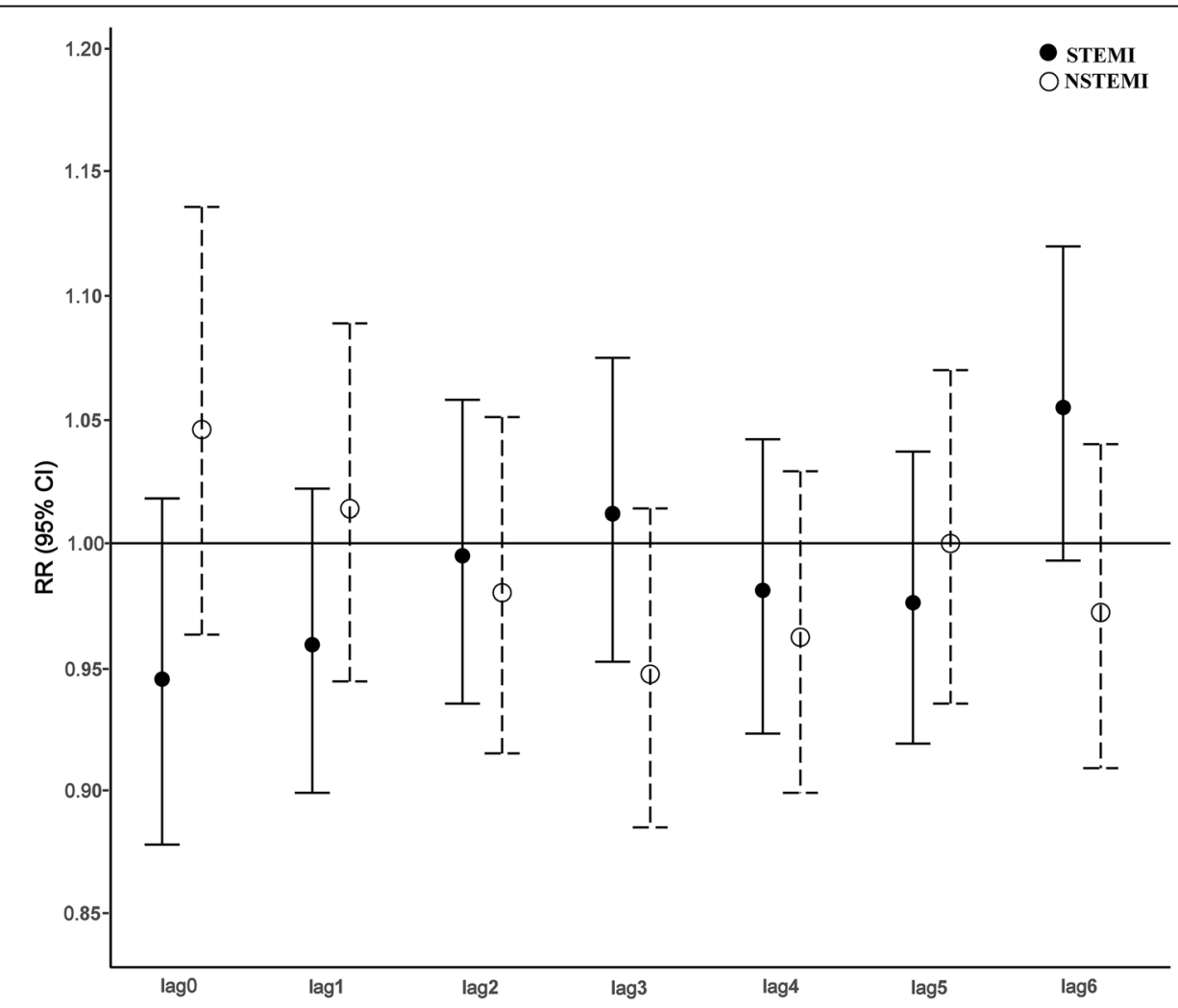

Fig. $1 \mathrm{RRS}^{1}$ of ST elevation myocardial infarction (STEMI) and non-STEMI (NSTEMI) associated with dust days. Single lags are shown for the current day (lag 0) to 6 days (lag 6). Comparison with non-dust days according to lag days in 2005-2017 (Relative risks with 95\% confidence interval) 


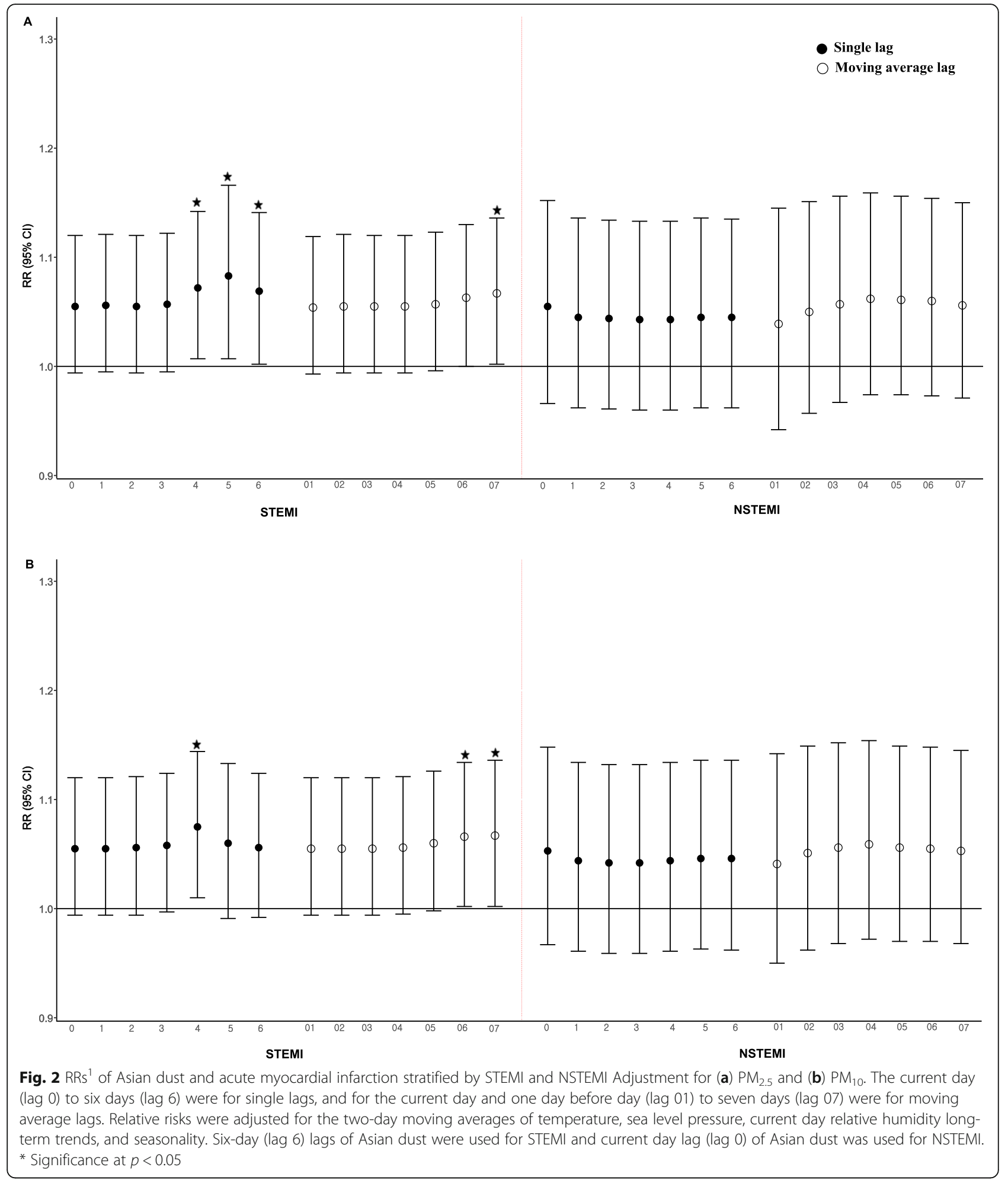

and current smoking groups in the $\mathrm{PM}_{2.5}$ models (Additional file 4). Data in Additional file 5 suggest robust associations between Asian dust and STEMI after adjustment for $\mathrm{PM}_{2.5}$ (Additional file 5).

\section{Discussion}

This study clarifies how PM impacts the effects of Asian dust on AMI incidence. The data showed no significant association between Asian dust and AMI at any lag; 

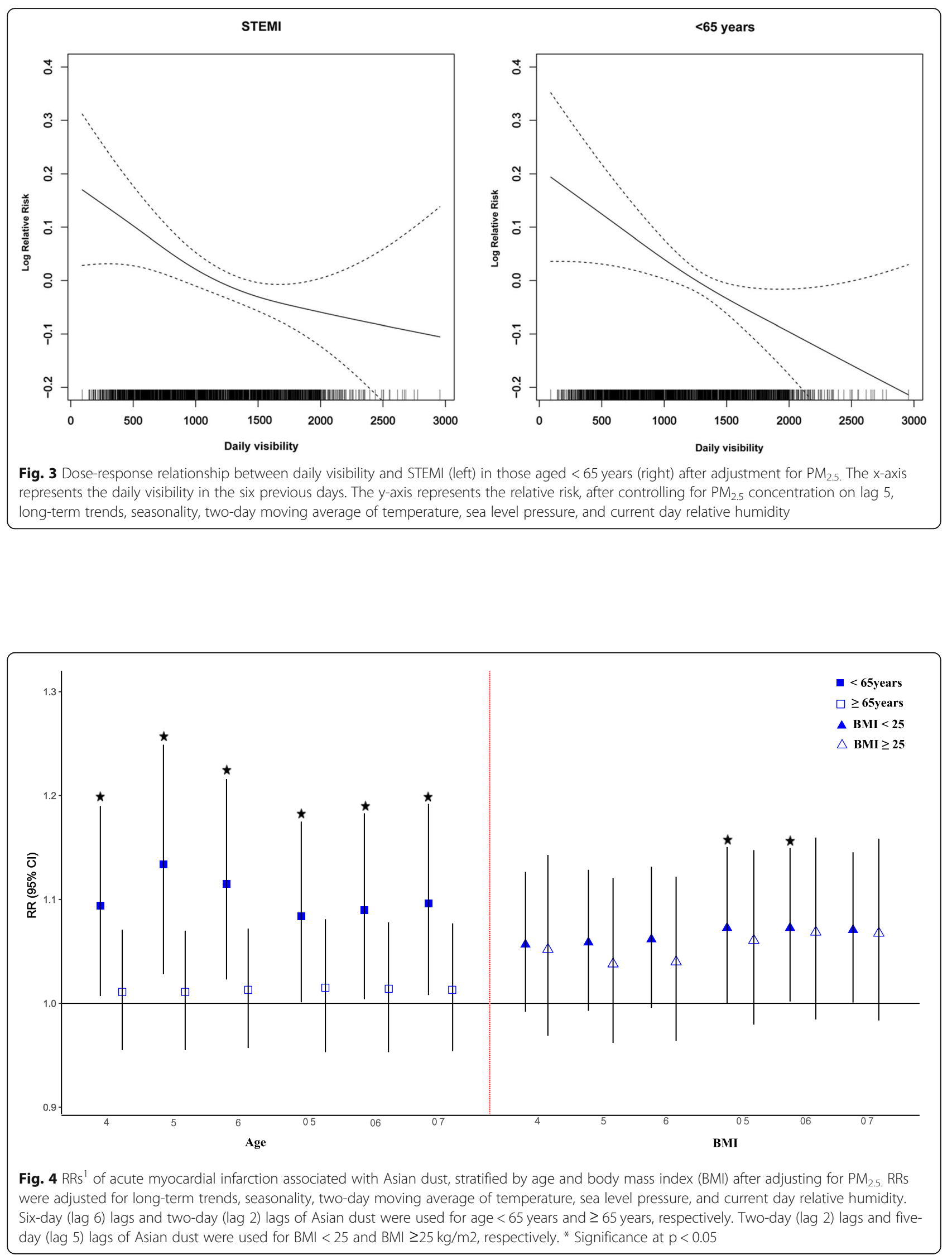
however, the association became significant after adjustment for $\mathrm{PM}_{2.5}$ and $\mathrm{PM}_{10}$, and thus, $\mathrm{PM}$ might have increased the effect of Asian dust on AMI risk. More importantly, both $\mathrm{PM}_{2.5}$ and $\mathrm{PM}_{10}$ enhanced the impact of Asian dust on increased risk for STEMI, but not for NSTEMI; this is consistent with findings of prior studies $[8,10]$. In addition, RRs for AMI were significantly higher in the $<65$-year-old and $\mathrm{BMI}<25$ groups than in the $\geq 65$-year-old and BMI $\geq 25 \mathrm{~kg} / \mathrm{m}^{2}$ groups. In particular, this is the first study to show the relationship between daily average visibility-adjusted PM concentrations and STEMI. The results suggest the presence of an approximately negative linear exposure-response curve between visibility and STEMI; moreover, these results suggest that the visibility degradation's effects on the incidence of STEMI varied according to $\mathrm{PM}_{2.5}$.

Evidence of the risk of MI with short-term exposure to PM has been widely reported. A meta-analysis by Mustafic et al. that combined estimates of 34 eligible research suggested that short-term exposure to PM increased the risk of MI [20]. Most studies have focused on AMI as the health outcome; however, interest has shifted to specific subsets of AMI more recently. For instance, Gardner et al. provided information on the relationship between $\mathrm{PM}_{2.5}$ exposure STEMI and, rather than NSTEMI [9]. Consistent with this, a recent study in China similarly showed that $\mathrm{PM}_{2.5}$ may increase the risk of STEMI but not NSTEMI [10]; these are consistent with the present findings.

Numerous studies have reported the health effects of Asian dust exposure; however, relatively few studies have focused on AMI onset, possibly due to insufficient sample size regarding AMI incidence within the relevant geographic area. Matsukawa et al. suggested that exposure to Asian dust a few days before admission is associated with the incidence of AMI [4]; thus, Asian dust may be a trigger of AMI. Nevertheless, there is still inadequate understanding on how PM affects the association of AMI with Asian dust that is further complicated by inconsistent reports. For example, Crooks et al. observed associations of dust storms and $\mathrm{PM}_{10}$ with $\mathrm{AMI}$ in the US [6]; but not of dust storms with $\mathrm{PM}_{2.5}$. Furthermore, Neophytou et al. reported a study in Cyprus wherein a positive effect of dust day $\mathrm{PM}_{10}$ on cardiovascular mortality was observed; however, the association steadily decreased on non-dust days [21]. For the effects of $\mathrm{PM}_{2.5}$, Kim et al. reported that cardiovascular mortality was significantly associated with $\mathrm{PM}_{2.5}$ during Asian dust days in Korea [22]. Similarly, a recently conducted Japanese study by Kojima et al. observed that Asian dust increased the risk of AMI after controlling for $\mathrm{PM}_{2.5}$ [3]. However, contrary to this study's finding, the association with Asian dust was reported to be more pronounced for NSTEMI than for STEMI. The effects of $\mathrm{PM}_{2.5}$ on different subgroups of AMI may explain the inconsistent results observed in earlier studies.

Another important finding of the present analysis was that the effects of Asian dust exposure, alongside shortterm PM exposure, were substantially dependent on age and BMI. Contrary to comparable epidemiological studies wherein larger effects were observed in older individuals $[3,23]$, a stronger impact on the AMI onset was observed in the younger age group. The reason could be the participation of young people in many outdoor activities. Consistently, Chen et al. reported that the risk of emergency hospital visits for $\mathrm{PM}_{10}$ and $\mathrm{PM}_{2.5}$ was slightly higher in the 46-64-year-old age group than in the $\geq 65$-year-old age group [24]. In addition, this study showed that the effect of Asian dust with short-term PM exposure was greater in the $\mathrm{BMI}<25$ group than in the BMI $\geq 25$ group. Andersen et al. similarly reported that enhanced air pollution effects were not observed with increasing BMI [25]. On the contrary, Miller et al. showed a stronger association between cardiovascular disease and $\mathrm{PM}_{2.5}$ concentration with increasing obesity [26]. However, after stratifying the effects of Asian dust by BMI status exclusively, a higher risk was observed in overweight people (data not provided). Although it is well-known that smoking increases the risk of AMI [27], epidemiologic evidence assessing the effects of PM by smoking status is sparse, owing to inadequate data. The results indicate that past smokers have a higher risk of AMI onset than never smokers and current smokers; however, this difference was not significant. Similar results were reported for smokers in the US, where a range of $8-18 \%$ increase in cardiovascular mortality per $10 \mu \mathrm{m} / \mathrm{m}^{3}$ increase in ambient PM was estimated relative to the risk in nonsmokers [28]. These findings suggest that the physiological characteristics and underlying factors of specific populations, such as those based on smoking habit, BMI, or age, likely differed regarding their contribution to Asian dust susceptibility. Furthermore, many complex factors contribute to differences in weather conditions and topography; therefore, the current findings require replication.

Some plausible mechanisms have been suggested for the association of Asian dust with adverse health effects. Zhang et al. reported that the particle sizes in Asian dust range from 1 to $8 \mu \mathrm{m}$ (median, $3 \mu \mathrm{m}$ ), which indicates relatively small particles in the $\mathrm{PM}_{2.5}$ size range [29]. Therefore, PM in Asian dust storms could have a similar pathophysiological mechanism regarding the effects on human health as urban PM can lead to systemic oxidative stress or systemic inflammation. These effects could subsequently induce a cascade reaction within the cardiovascular system [30]. Studies on experimental rats in Japan [31] and Taiwan [32] observed inflammatory- and severe toxicity effects of Asian dust storms on blood 
pressure and heart rates. However, detailed mechanisms underlying AMI onset due to Asian dust exposure remain unclear; this may be because determining the precise composition of Asian dust is complex [33]. Similarly, desert dust moves microorganisms and bioparticulates, such as fungi, viruses, bacteria, and pollen, as well as related lipid components and protein [34]. Further studies are warranted to determine the relationship between the aforementioned components and the increase in AMI incidence.

To the best of our knowledge, this study is the first to thoroughly investigate the dose-response relationship between visibility and STEMI incidence. The results suggest an approximately negative linear exposure-response curve and indicate that visibility degradation varies according to $\mathrm{PM}_{2.5}$ concentrations. Similar results were reported by Huang et al. in Shanghai, China [35], who were the first to graphically present the exposureresponse relationship between visibility and cardiovascular mortality and show that the exposure-response curve exhibits a negative linear relationship. Some studies assumed an exponential relationship between $\mathrm{PM}_{2.5}$ and visibility, with higher $\mathrm{PM}_{2.5}$ concentrations corresponding to lower visibility [36]. These studies support a relationship between visibility and $\mathrm{PM}_{2.5}$ and $\mathrm{PM}_{10}$ concentrations and thus clarify the relationship between visibility and cardiovascular events.

This study exhibits a number of strengths. First, a long study period and a relatively large sample size from the KAMIR database were used; the KAMIR is a prospective, open, observational, multi-center on-line registry on AMI. In contrast, other studies have been limited to a short temporal scope and a small number of patients. Second, arrival time at the hospital due to AMI symptoms was used rather than hospital admission day. Therefore, the data provide novel insights into the mechanisms by which PM exposure may increase risk of AMI associated with Asian dust. Third, estimates from the models were quite robust in relation to inclusion of the weather variables, the use of interaction terms between the daily means of visibility and humidity, and varying lagged structures of PM.

However, this study equally has a number of limitations. First, the ambient air pollution concentration was used as proxy exposure from an air pollution monitoring site rather than personal exposure levels. However, a previous study reported that outdoor air pollution exposure and personal $\mathrm{PM}_{2.5}$ exposure seemed particularly problematic, as personal exposure can widely vary depending on lifestyle choices, such as time-activity patterns of individuals, occupational characteristics, and residential environment [37]. Although previous timeseries studies used a common approach that relied on exposure data from a single monitoring station to reflect outdoor pollution in the study area, exposure data from 27 monitoring stations spread geographically across Seoul were used, computed by averaging the daily mean concentrations across all stations. In this study, systematic differences between areas in the measurement of covariates. Second, data concerning the chemical and biological composition of Asian dust were not included. Accordingly, a further study including the composition and toxicity of Asian dust is necessary.

\section{Conclusions}

This study provides new insights regarding the effects of PM on AMI during Asian dust days. These results suggest that it is crucial to reduce $\mathrm{PM}_{2.5}$ and $\mathrm{PM}_{10}$ emissions, particularly during Asian dust days, and this would reduce the incidence of STEMI and AMI among young patients. Identifying modifier effects of PM could provide knowledge for future risk assessment studies.

\section{Supplementary Information}

The online version contains supplementary material available at https://doi. org/10.1186/s12889-020-10067-y

Additional file 1. Correlations between exposure variables during 2003 2013 in Seoul.

Additional file 2. Relative risks of AMI per $10 \mu \mathrm{g} / \mathrm{m}^{3}$ increase in currentday $\mathrm{PM}_{2.5}$ and $\mathrm{PM}_{10}$ concentrations by subgroup with single lags.

Additional file 3. Relative risk (RR) of Asian dust associated with acute myocardial infarction, stratified by age and body mass index (BMI) after adjusting for $\mathrm{PM}_{10}$

Additional file 4. Association between Asian dust and acute myocardial infarction by smoking status, after adjustment for $\mathrm{PM}_{2.5}$ by lag days.

Additional file 5. Relative risk (RR) of Asian dust associated with ST elevation myocardial infarction after adjustment for $\mathrm{PM}_{2.5}$ with single lag days (from current day to the previous 6 days): results of the main analyses models and sensitivity analyses models.

\section{Abbreviations}

AMI: Acute myocardial infarction; PM: Particulate matter; Ml: Myocardial infarction; STEMI: ST-elevation MI; NSTEMI: Non ST-elevation MI; RR: Relative risk: Cl: Confidence interval; KAMIR: Korea Acute Myocardial Infarction Registry; BMl: Body mass index

\section{Acknowledgements}

Not applicable.

Authors' contributions

SL conducted research design and drafted the manuscript. SL and WL conducted the statistical analysis. EL, MHJ, SWR, CJK, SCC, HSK and HCG conducted acquisition of data. HK provided the final approval of the manuscript version to be submitted. All authors read and approved the final manuscript.

\section{Funding}

This work was supported by the Korea Ministry of Environment as a Climate Change Correspondence Program [grant number 2014001310007] and the Korea Centers for Disease Control and Prevention [grant number 2016ER6304-01]

\section{Availability of data and materials}

The data that support the findings are available from [Korea Centers for Disease Control and Prevention] but restrictions apply to the availability of 
these data, which were used under license for the current study, and so are not publicly available. Data are however available from the authors upon reasonable request and with permission of [Korea Centers for Disease Control and Prevention].

\section{Ethics approval and consent to participate}

Not applicable.

\section{Consent for publication}

Not applicable.

\section{Competing interests}

The authors declare that they have no competing interests.

\section{Author details}

${ }^{1}$ Institute of Health and Environment, Seoul National University, Gwanak-ro, Seoul 08826, Republic of Korea. ${ }^{2}$ Department of Biostatistics and Epidemiology, Graduate School of Public Health, Seoul National University, Gwanak-gu, Seoul 00826, Republic of Korea. ${ }^{3}$ Department of Preventive Medicine, College of Medicine, South Korea University, Anam-ro, Seoul 03080, Republic of Korea. ${ }^{4}$ Chonnam National University Hospital, Jebong-ro, Gwangju 61469, South Korea. ${ }^{5}$ Korea University Guro Hospital, Gurodong-ro, Seoul 08308, South Korea. ${ }^{6}$ Kyunghee University Hospital at Gangdong, Gangdong-gu, 05278 Seoul, Republic of Korea. ${ }^{7}$ Department of Internal Medicine, Kyungpook National University Hospital, Jung-gu, 41940 Daegu, Republic of Korea. ${ }^{8}$ School of Medicine, Kyungpook National University, Jung-gu, 41940 Daegu, Republic of Korea. 'Department of Internal Medicine, Seoul National University Hospital, Jongno-gu, 03080 Seoul, Republic of Korea. ${ }^{10}$ Samsung Medical Center, Sungkyunkwan University School of Medicine, Gangnam-gu, 06351 Seoul, Republic of Korea.

Received: 3 June 2020 Accepted: 14 December 2020

Published online: 07 January 2021

\section{References}

1. Goudie AS. Desert dust and human health disorders. Environ Int. 2014;63: 101-13.

2. Meng Z, Lu B. Dust events as a risk factor for daily hospitalization for respiratory and cardiovascular diseases in Minqin. China Atmos Environ. 2007:41:7048-58.

3. Kojima S, Michikawa T, Ueda K, Sakamoto T, Matsui K, Kojima T, et al. Asian dust exposure triggers acute myocardial infarction. Eur Heart J. 2017;38: 3202-8

4. Matsukawa R, Michikawa T, Ueda K, Nitta H, Kawasaki T, Tashiro H, et al. Desert dust is a risk factor for the incidence of acute myocardial infarction in western Japan. Circ Cardiovasc Qual Outcomes. 2014;7:743-8.

5. Alessandrini ER, Stafoggia M, Faustini A, Gobbi GP, Forastiere F. Saharan dust and the association between particulate matter and daily hospitalisations in Rome. Italy Occup Environ Med. 2013;70:432-4.

6. Crooks JL, Cascio WE, Percy MS, Reyes J, Neas LM, Hilborn ED. The association between dust storms and daily non-accidental mortality in the United States, 1993-2005. Environ Health Perspect. 2016:124:1735-43.

7. Merrifield A, Schindeler S, Jalaludin B, Smith W. Health effects of the September 2009 dust storm in Sydney, Australia: did emergency department visits and hospital admissions increase? Environ Health. 2013;12:32

8. Argacha JF, Collart P, Wauters A, Kayaert P, Lochy S, Schoors D, et al. Air pollution and ST-elevation myocardial infarction: a case-crossover study of the Belgian STEMI registry 2009-2013. Int J Cardiol. 2016;223:300-5.

9. Gardner B, Ling F, Hopke PK, Frampton MW, Utell MJ, Zareba W, et al. Ambient fine particulate air pollution triggers ST-elevation myocardial infarction, but not non-ST elevation myocardial infarction: a case-crossover study. Part Fibre Toxicol. 2014;11:1.

10. Liu H, Tian Y, Cao Y, Frampton MW, Utell MJ, Zareba W, et al. Fine particulate air pollution and hospital admissions and readmissions for acute myocardial infarction in 26 Chinese cities. Chemosphere. 2018;192:282-8

11. Pope CA, Muhlestein JB, Anderson JL, Cannon JB, Hales NM, Meredith KG, et al. Short-term exposure to fine particulate matter air pollution is preferentially associated with the risk of ST-segment elevation acute coronary events. J Am Heart Assoc. 2015;4:e002506.
12. Bentzon JF, Falk E. Pathogenesis of stable and acute coronary syndromes. Acute coronary syndromes; Elsevier Saunders; 2011. p. 42-52.

13. Caussin C, Escolano S, Mustafic H, Bataille S, Tafflet M, Chatignoux E, et al. Short-term exposure to environmental parameters and onset of ST elevation myocardial infarction. The CARDIO-ARSIF registry Int J Cardiol. 2015;183:17-23.

14. Wang $X$, Kindzierski $W$, Kaul $P$. Comparison of transient associations of air pollution and AMI hospitalisation in two cities of Alberta, Canada, using a case-crossover design. BMJ Open. 2015;5:e009169.

15. Stafoggia M, Samoli E, Alessandrini E, Cadum E, Ostro B, Berti G, et al. Short-term associations between fine and coarse particulate matter and hospitalizations in southern Europe: results from the MED-PARTICLES project. Environ Health Perspect. 2013:121:1026-33.

16. Lee S, Choi B, Yi SM, Ko G. Characterization of microbial community during Asian dust events in Korea. Sci Total Environ. 2009:407:5308-14.

17. Guo J, Rahn KA, Zhuang GS. A mechanism for the increase of pollution elements in dust storms in Beijing. Atmos Environ. 2004;38:855-62.

18. Lee SR, Jeong MH, Ahn YK, Chae SC, Hur SH, Kim YJ, et al. Clinical safety of drug-eluting stents in the Korea acute myocardial infarction registry. Circ J. 2008;72:392-8

19. World Health Organization. The Asia-Pacific perspective: redefining obesity and its treatment. Sydney: Health Communications Australia; 2000.

20. Mustafic H, Jabre P, Caussin C, Murad MH, Escolano S, Tafflet M, et al. Main air pollutants and myocardial infarction: a systematic review and metaanalysis. JAMA. 2012;307:713-21.

21. Neophytou AM, Yiallouros P, Coull BA, Kleanthous S, Pavlou P, Pashiardis $S$, et al. Particulate matter concentrations during desert dust outbreaks and daily mortality in Nicosia. Cyprus J Expo Sci Environ Epidemiol. 2013;23:275-80.

22. Kim HS, Kim DS, Kim H, Yi SM. Relationship between mortality and fine particles during Asian dust, smog-Asian dust, and smog days in Korea. Int J Environ Health Res. 2012;22:518-30.

23. Zhang Q, Qi W, Yao W, Wang M, Chen Y, Zhou Y. Ambient particulate matter $\left(\mathrm{PM}_{25} / \mathrm{PM}_{10}\right)$ exposure and emergency department visits for acute myocardial infarction in Chaoyang District, Beijing, China during 2014: a case-crossover study. J Epidemiol. 2016:26:538-45.

24. Chen G, Li S, Zhang Y, Zhang W, Li D, Wei X, et al. Effects of ambient PM, air pollution on daily emergency hospital visits in China: an epidemiological study. Lancet Planet Health. 2017;1:e221-9.

25. Andersen ZJ, Raaschou-Nielsen O, Ketzel M, Jensen SS, Hvidberg M, Loft S, et al. Diabetes incidence and long-term exposure to air pollution: a cohort study. Diabetes Care. 2012;35:92-8.

26. Miller KA, Siscovick DS, Sheppard L, Shepherd K, Sullivan JH, Anderson GL, et al. Long-term exposure to air pollution and incidence of cardiovascular events in women. N Engl J Med. 2007;356:447-58.

27. Nyboe J, Jensen G, Appleyard M, Schnohr P. Smoking and the risk of first acute myocardial infarction. Am Heart J. 1991:122:438-47.

28. Pope CA, Burnett RT, Thurston GD, Thun MJ, Calle EE, Krewski D, et al. Cardiovascular mortality and long-term exposure to particulate air pollution: epidemiological evidence of general pathophysiological pathways of disease. Circulation. 2004:109:71-7.

29. Zhang DZ, Iwasaka Y, Shi GY, Zang JY, Matsuki A, Trochkine D. Mixture state and size of Asian dust particles collected at southwestern Japan in spring 2000. J Geophys Res Atmos. 2003;108:1-12.

30. Chuang KJ, Chan CC, Su TC, Lee CT, Tang CS. The effect of urban air pollution on inflammation, oxidative stress, coagulation, and autonomic dysfunction in young adults. Am J Respir Crit Care Med. 2007;176:370-6

31. Ichinose T, Sadakane K, Takano H, Yanagisawa R, Nishikawa M, Mori I, et al. Enhancement of mite allergen-induced eosinophil infiltration in the murine airway and local cytokine/chemokine expression by Asian sand dust. J Toxicol Environ Health A. 2006:69:1571-85.

32. Lei YC, Chan CC, Wang PY, Lee CT, Cheng TJ. Effects of Asian dust event particles on inflammation markers in peripheral blood and bronchoalveolar lavage in pulmonary hypertensive rats. Environ Res. 2004;95:71-6.

33. Li G, Chen J, Ji J, Yang J, Conway TM. Natural and anthropogenic sources of east Asian dust. Geology. 2009:37:727-30.

34. Gonzalez-Martin C, Teigell-Perez N, Valladares B, Griffin DW. The global dispersion of pathogenic microorganisms by dust storms and its relevance to agriculture. Adv Agron. 2014;127:1-41. 
35. Huang W, Tan J, Kan H, Zhao N, Song W, Song G, et al. Visibility, air quality and daily mortality in Shanghai. China Sci Total Environ. 2009: 407:3295-300

36. Deng XJ, Tie XX, Wu D, Zhou X, Bi X, Tan H, et al. Long-term trend of visibility and its characterizations in the Pearl River Delta (PRD) regionChina. Atmos Environ. 2008;42:1424-35.

37. Oglesby L, Künzli N, Röösli M, Braun-Fahrländer C, Mathys P, Stern W, et al. Validity of ambient levels of fine particles as surrogate for personal exposure to outdoor air pollution - results of the European EXPOLIS-EAS study (Swiss center Basel). J Air Waste Manage Assoc. 2000;50:1251-61.

\section{Publisher's Note}

Springer Nature remains neutral with regard to jurisdictional claims in published maps and institutional affiliations.

Ready to submit your research? Choose BMC and benefit from:

- fast, convenient online submission

- thorough peer review by experienced researchers in your field

- rapid publication on acceptance

- support for research data, including large and complex data types

- gold Open Access which fosters wider collaboration and increased citations

- maximum visibility for your research: over $100 \mathrm{M}$ website views per year

At $B M C$, research is always in progress.

Learn more biomedcentral.com/submissions 